\title{
New Technologies for Producing Bicycle Hub Forging
}

\author{
Andrzej Gontarz ${ }^{1}$, Anna Dziubińska ${ }^{1}$, Grzegorz Winiarski ${ }^{1}$ and Arkadiusz Tofil ${ }^{2}$ \\ ${ }^{1}$ Mechanical Engineering Faculty, Lublin University of Technology, Nadbystrzycka 36, 20-618 Lublin, Poland \\ ${ }^{2}$ The State School of Higher Education in Chełm, Pocztowa 54, 22-100 Chełm, Poland
}

\begin{abstract}
The paper presents the results of research on two new forging processes for producing bicycle hub forgings in a three-slide forging press. The first process is related to producing a forging with an axial cavity by flashless forging. The other one concerns the production of a forging from a tube billet. The potential benefits offered by these two new forging processes compared to the conventional hammer forging method for producing hubs are discussed. The designed processes are verified theoretically via numerical simulations. The first of the proposed processes is also subjected to experimental verification. The results demonstrate that the new technologies allow obtaining good quality products. A comparison is made between material and energy consumption in the two analyzed processes and in conventional hammer forging. It is found that the application of the forging process in a three-slide forging press leads to a considerable decrease in manufacturing costs.
\end{abstract}

\section{Introduction}

One of the trends in the development of metal forming technologies is designing energy- and material-saving production methods. Given such trend, a new forging press equipped with three movable slides (one vertical slide and two horizontal slides, each hydraulically-driven) has been designed and made (Fig. 1). The three-slide forging press (TSFP) offers more technological possibilities than conventional forging presses. One significant advantage of this press described in [1] is the possibility of employing material-saving technologies, for example a forging process for producing a valve housing with three cavities, which results in material savings by approx. 63\% (Fig. 2a). Another example of such technologies presented in [2] is flashless forging for producing connecting-rods, which - compared to conventional technologies - leads to reducing material consumption by about 30\% (Fig. 2e). The use of a TSFP gives the possibility of producing many other forgings that cannot be produced with conventional forging machines or the application of these machines is less effective. Such products include: cranked parts, solid and hollow elongated parts with bosses, flat parts with ribs, and many more (Fig. 2). Most TSFP-based forging processes are flashless, which ensures better grain flow in the final product and, consequently, enhanced mechanical properties of such product.

This paper presents the theoretical and experimental results of two new forging technologies for producing a bicycle wheel hub in a three-slide forging press. The shape and dimensions of the finished product are shown in Fig. 3. The hub belongs to the group of hollow parts with an elongated axis and bosses on their ends.

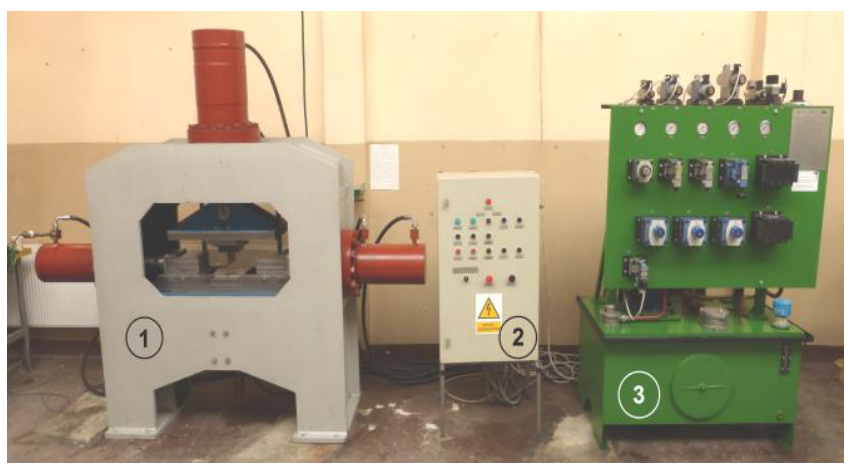

Figure 1. Three-slide forging press; 1 - mechanical system, 2 control system, 3 - hydraulic drive system.

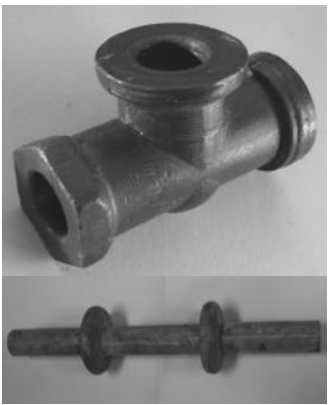

e)

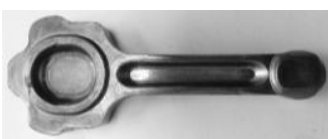

b)

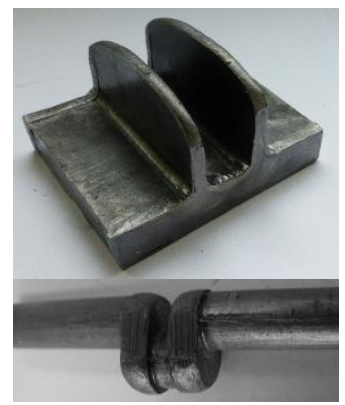

f)

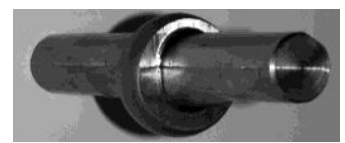

Figure 2. Examples of parts produced in a three-slide forging press: a) valve housing with three cavities, b) flat part with ribs, c) elongated parts, d) crank, e) flashless forged connecting rod, f) eccentric part [1-3]. 
Most often, such parts are made as full forgings, and then an axial hole is made by machining methods. There are also metal forming methods that allow obtaining a hollow product. One of them is cross-wedge rolling [4-6]. However, the ovalization of the cross-section of the product is the limitation of this method. This adverse effect can be reduced by using internal mandrels during rolling [7, 8]. The effective method of forming hollow parts is also rotary compression [9]. This technology involves the use of three rollers between which the hollow workpiece is formed. An interesting technology is also spin extrusion of hollow products based on $7 \mathrm{NC}$ axies machining [10].

a)

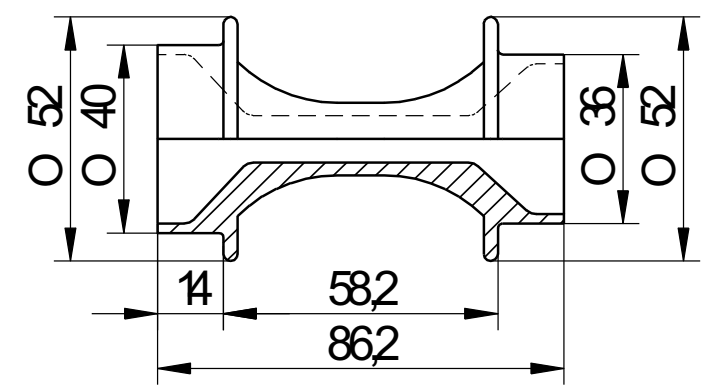

b)

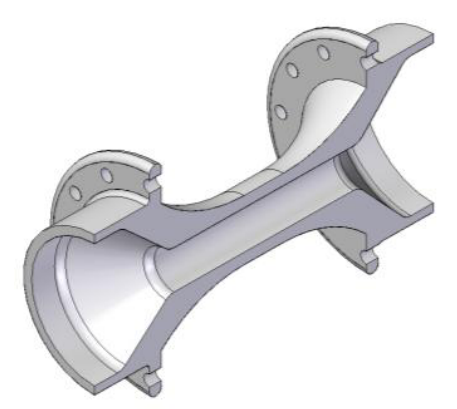

Figure 3. Bicycle wheel hub - final product: a) draft with main dimensions, b) isometric view - cross section.

It should be noted that the new technologies described in this paper can be applied to produce other parts that have a shape similar to that of the investigated hub, including parts for the automotive and aircraft industries. The main objective of the present research was to develop technologies that would ensure the highest material and energy savings compared to the conventionally used forging process for producing hubs.

\section{Conventional forging technology for hubs}

Nowadays a bicycle hub forging with the shape and dimensions illustrated in Fig. 4 is produced by die hammer forging. Such forging is worked into a finished product by machining, which involves removing technological allowances and drilling an axial hole. In this process, the hammer strikes with an energy of $32 \mathrm{~kJ}$. The billet is a bar with a diameter of $\varnothing 45 \mathrm{~mm}$ and a length of $115 \mathrm{~mm}$, made of aluminum alloy AlCu2SiMn that has the following chemical composition: $\mathrm{Si}$ $0.7 \div 1.2 \%, \mathrm{Fe}-0.7 \%, \mathrm{Cu}-1.8 \div 2.6 \%, \mathrm{Mn}-0.4 \div 0.8, \mathrm{Mg}$ $-0.4 \div 0.8, \mathrm{Cr}-0.2 \%, \mathrm{Ni}-0.1 \%, \mathrm{Zn}-0.2 \%$, Ti $-0.1 \%$, other - $\leqslant 0.15 \%, \mathrm{Al}$ - rest. The process involves the following operations (Fig. 5):

- upsetting heated billet to a height of approx. $73 \div 75 \mathrm{~mm}$ (Fig. 5b),

- initial die forging at $2 \div 3$ hammer blows (Fig. 5c),

- final die forging at $2 \div 3$ hammer blows (Fig. 5d),

- flash trimming (Fig. 5e).

a)

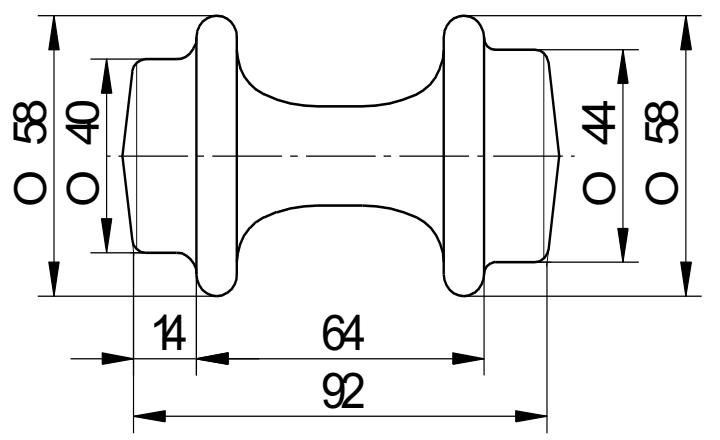

b)

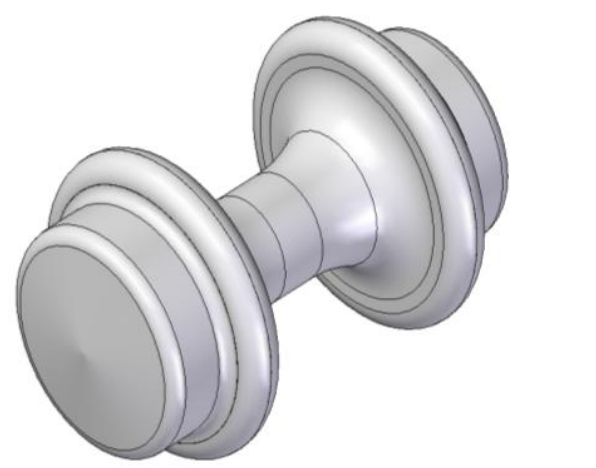

Figure 4. Bicycle wheel hub forging produced by die hammer forging: a) draft with main dimensions, b) isometric view. a)

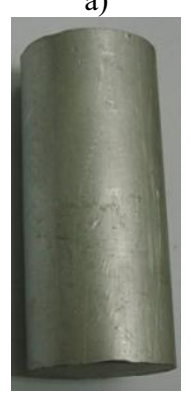

d)

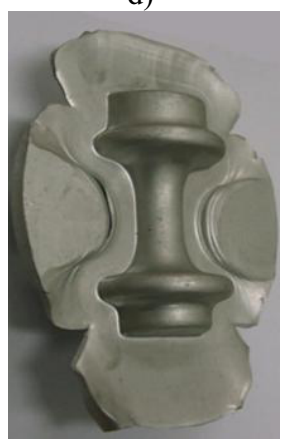

b)

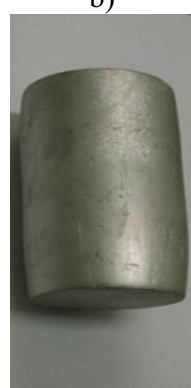

e)

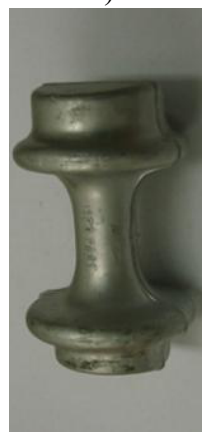

c)

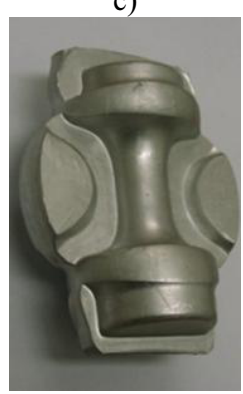

f)

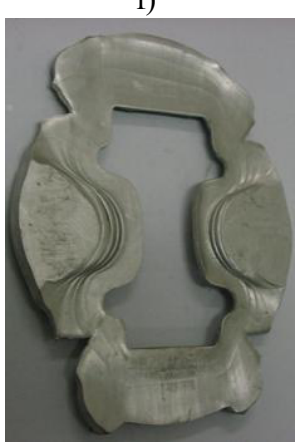

Figure 5. Successive stages of the process for producing a bicycle wheel hub forging by the hammer forging method: a) billet, b) upsetting, c) initial die forging, d) final die forging, e) finished product, f) flash. 
Due to a relatively high cross-sectional difference in the heads and shank of the forging, flash amounts to approx. $41 \%$ of the billet volume. Taking into account additional material losses generated in the course of machining, it can be observed that the volume of the finished product is only about $19 \%$ of the volume of the billet. Owing to the substantial material consumption in the process, it is justified that new, TSFP-based materialsaving technologies be developed.

\section{New forging technology - Variant I}

In the first variant of a new TSFP-based forging technology, a bar is clamped by the upper die driven by the vertical slide; then, bosses with axial cavities are formed on bar ends by the side punches that are driven by the horizontal slides (Fig. 6). Fig. 7 shows the shape and dimensions of a forging that can be produced by this method. Compared to forgings produced by the hammer forging method, the forging obtained with the new technology exhibits a lower weight, which results from applying some differences to the forging design.

a)

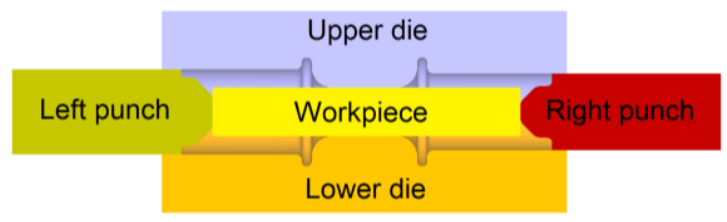

b)

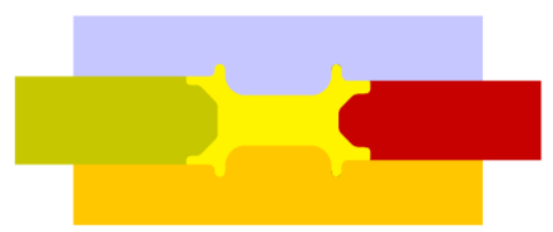

Figure 6. Design of the TSFP-based forging method for producing a bicycle wheel hub forging according to Variant I: a) start of the process, $b$ ) end of the process.

a)

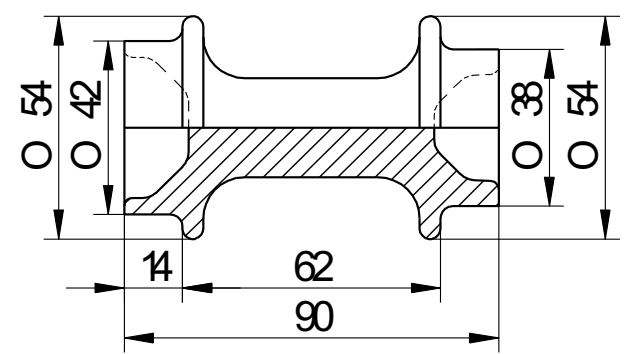

b)

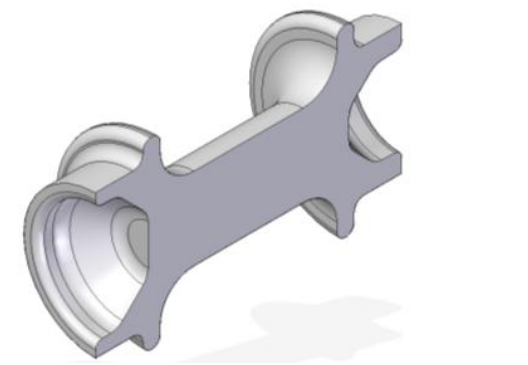

Figure 7. Bicycle wheel hub forging produced in a TSFP according to Variant I: a) draft with main dimensions, b) isometric view.
They included:

- the application of smaller technological allowances due to more precise guiding of the tools,

- the omission of forging inclinations,

- making two axial cavities.

Owing to the shape of the forging, technological allowances had to be added in the shank, too. The head diameters of $\varnothing 38 \mathrm{~mm}$ and $\varnothing 42 \mathrm{~mm}$ are too high to run the forging process from a billet whose diameter corresponds to the diameter of a necking in the hub shank, this diameter being $\varnothing 20.5 \mathrm{~mm}$. If the process were conducted under such conditions, the billet would undergo buckling, which would result in producing a forging with defects. To avoid this, the diameter of the forging shank was set to $\varnothing 24 \mathrm{~mm}$. The application of the billet with the same diameter means that the upsetting ratios defined as the length-to-diameter ratio of the unconstrained part of the billet do not exceed the value of 2.6. Such geometrical parameters meet the required boundary conditions of forming, which will ensure process stability. When designing the forging, the shape of its shank was changed from spool-like to cylindrical, which significantly improves the position stability of the billet in the impression. It was assumed that the forging would be produced from a bar with a diameter of $\varnothing 24 \mathrm{~mm}$ and a length of $155 \mathrm{~mm}$. The solutions were numerically simulated prior to constructing tools and conducting experiments.

Calculations were made assuming three-dimensional state of strain and thermo-mechanical model of the process. Material model of aluminum alloy $\mathrm{AlCu} 2 \mathrm{SiMn}$ was assumed on the basis of the results presented in [11]. Friction conditions while forming in hot conditions with lubrication of tallow base lubricant with graphite for the friction pair aluminum alloy - tool steel were described by constant friction model, yet, the value of friction factor $\mathrm{m}=0.15$ was also assumed according to [12].

It was assumed that the billet was heated to a temperature of $420^{\circ} \mathrm{C}$, while the tools had a temperature of $250^{\circ} \mathrm{C}$. It was taken for granted that the heat transfer coefficient between the material and tool equaled $10 \mathrm{~kW} / \mathrm{m} 2 \mathrm{~K}$, and between the material and the environment 0.007 $\mathrm{kW} / \mathrm{m} 2 \mathrm{~K}$ [13].

Fig. 8 presents the changes in forging shape in the successive stages of the forging process; the figure also shows the distribution of strain in the section. The simulation results demonstrate that the forging is free from shape defects such as overlap or underfill. Also, the force exerted by individual tools on the whole forming process is examined (Fig. 9). As can be observed, the distributions of the forces are similar. At the initial stage of the process, the values of the forces of both the side punches and the upper die increase at a slow rate. At the final stage, when the flanges are being formed, the forces, however, considerably increase their values. It is worth noting that the radial force is approximately two times higher than the forces exerted by each of the side punches. The theoretical results obtained for force parameters confirm the suitability of using the three-slide forging press to produce the investigated forging. Consequently, the newly developed method was subjected to experimental verification. 

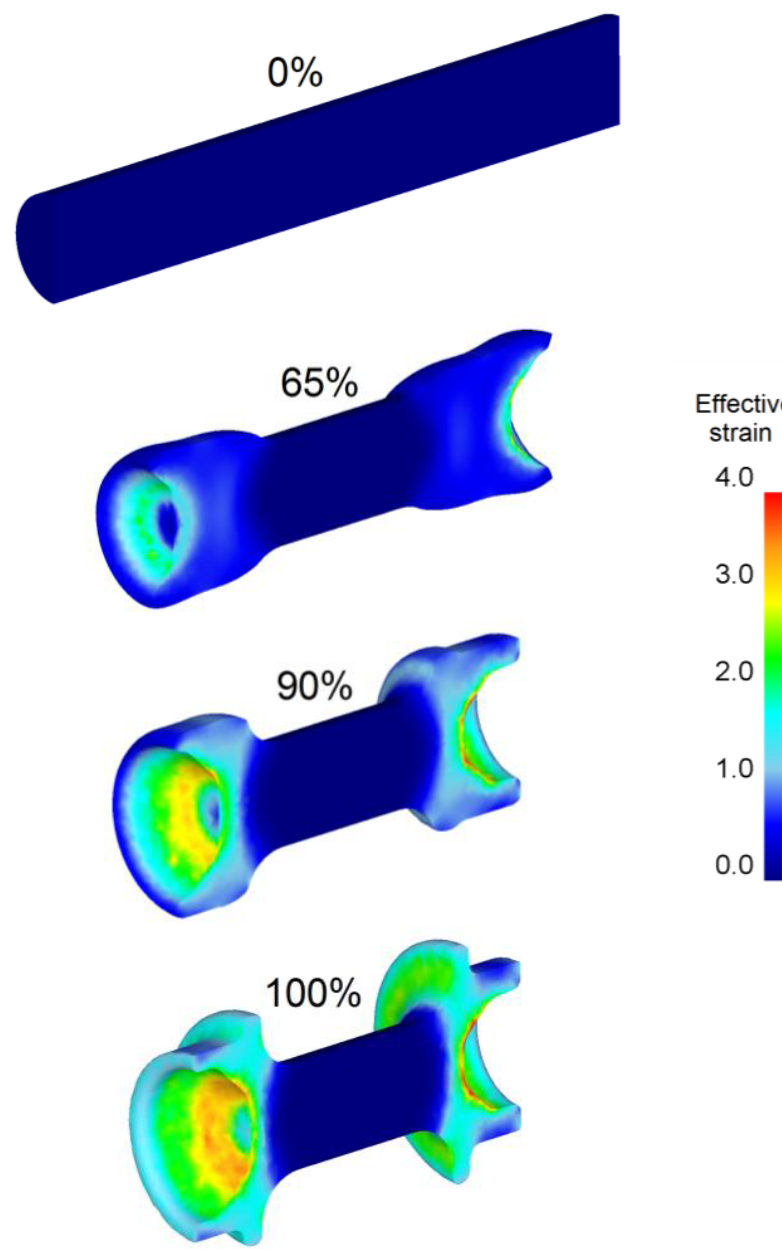

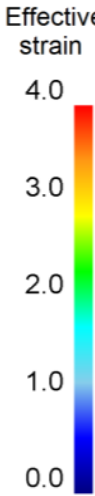

Figure 8. Shape changes in the successive stages of the process (given in the figure) and the distribution of strains in the axial section of a forging.

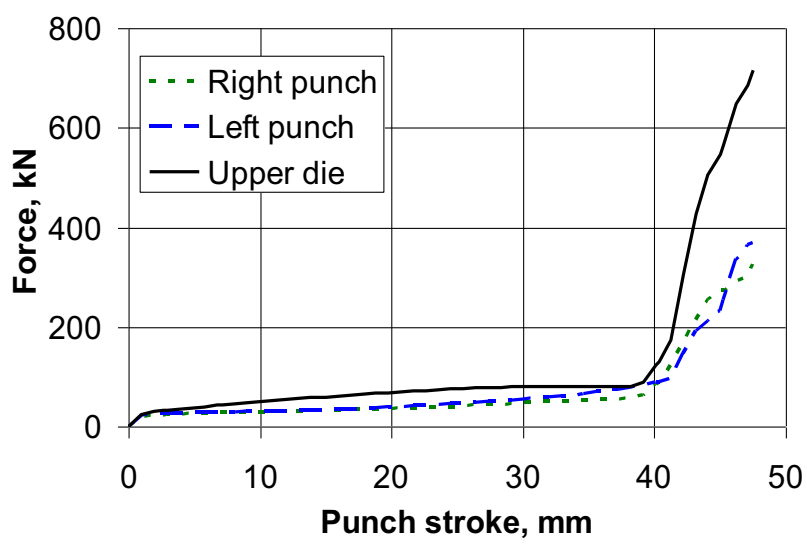

Figure 9. Distribution of forming forces in the process for a bicycle wheel hub according to Variant I - theoretical results.

To perform the experiments, a set of tools comprising two clamping dies and two side punches was made (Fig. 10a). As can be seen in Fig. 10b, the forging obtained in the experiments has the correct shape and dimensions. Hence, the experimental results confirm that a bicycle wheel hub can be produced by the designed variant of the forging process.
Finally, in Variant I the bicycle wheel hub forging was produced in one working cycle of the press. This results in a short forging time, which is of vital importance when forming aluminium alloys because they cool rapidly and have a narrow range of forging temperatures.

a)

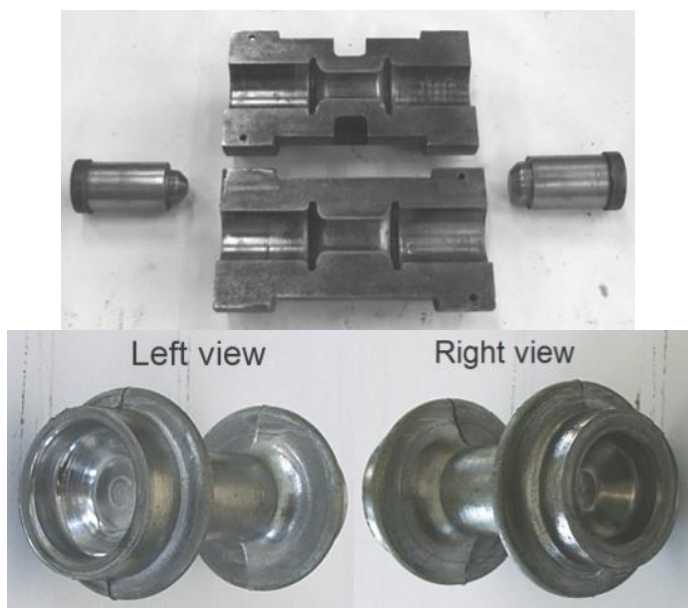

Figure 10. Experimental results - Variant I: a) tools used, b) produced bicycle hub.

\section{New forging technology - Variant II}

The design of Variant II of the forging process for producing a bicycle wheel hub in a TSFP is illustrated in Fig. 11. This process variant differs from Variant I with regard to billet type. The billet used in Variant II is a tube, which allows the production of a hollow part. One advantage of this solution is both a shorter time of machining an axial hole in the finished product and lower material consumption. In this process, the billet is first clamped between two dies, then flanged bosses on the billet ends are formed. Next, a mandrel is used to make an axial hole in the forging. This forging technology rests upon the assumption that the flanges are formed by open die forging so as not to restrain the material in the dies. Fig. 12 shows the shape and dimensions of a forging designed for this forging process variant. To verify the assumptions made, preliminary simulations were performed. The conditions applied in the theoretical analysis were identical as the ones applied to simulate Variant I of the forging process.

As demonstrated by the numerical results, there is overlap on the internal wall of the hole if the billet wall is too thin. It can be observed that the material flows radially to the outside at the flanges; hence it undergoes bending on the inside, which leads to overlap (Fig. 13). The results of the numerical simulations prove that the process will run correctly (without overlap) if a billet with an outside diameter of $\varnothing 24 \mathrm{~mm}$, an inside diameter of $\varnothing 8 \mathrm{~mm}$ and a length of $170 \mathrm{~mm}$ is used. Fig. 14 shows the correctly-run forging process for producing a bicycle wheel hub; the distributions of strain in the product are also shown in the figure. As can be seen in the figure, the highest values of strain occur in the regions of the cavities and flanges, while the lowest strains can be 
observed in the forging shank. Such distribution of strain results from the geometry of the process, in which only end parts of the material are subjected to forming, while the shank is not subjected to forming at all.

a)

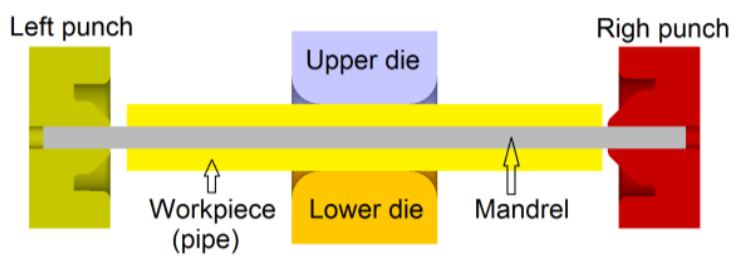

b)

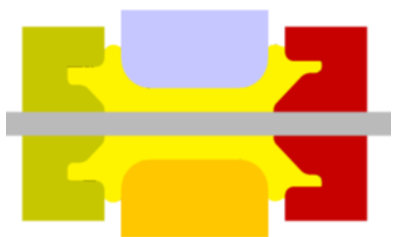

Figure 11. Scheme of TSFP-based forging process according to Variant II: a) start of process, b) end of process (cross section).

a)

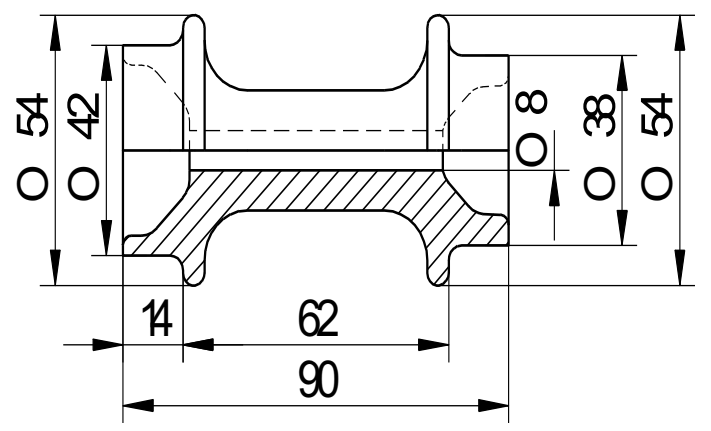

b)

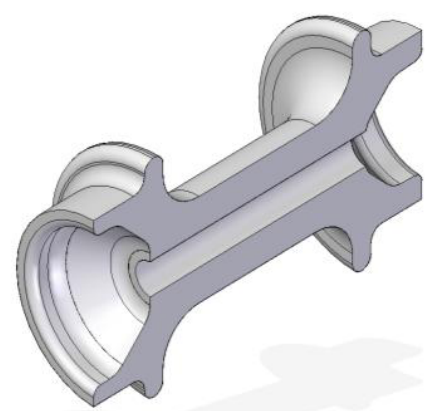

Figure 12. Forging produced in a TSFP according to Variant II: a) view with main dimensions, b) isometric view.
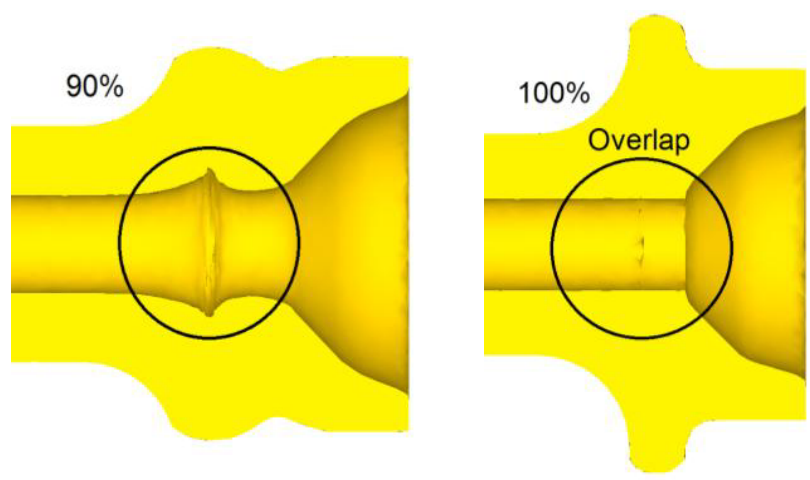

Figure 13. Incorrectly-run forging process in which a surface defect (overlap) occurs.
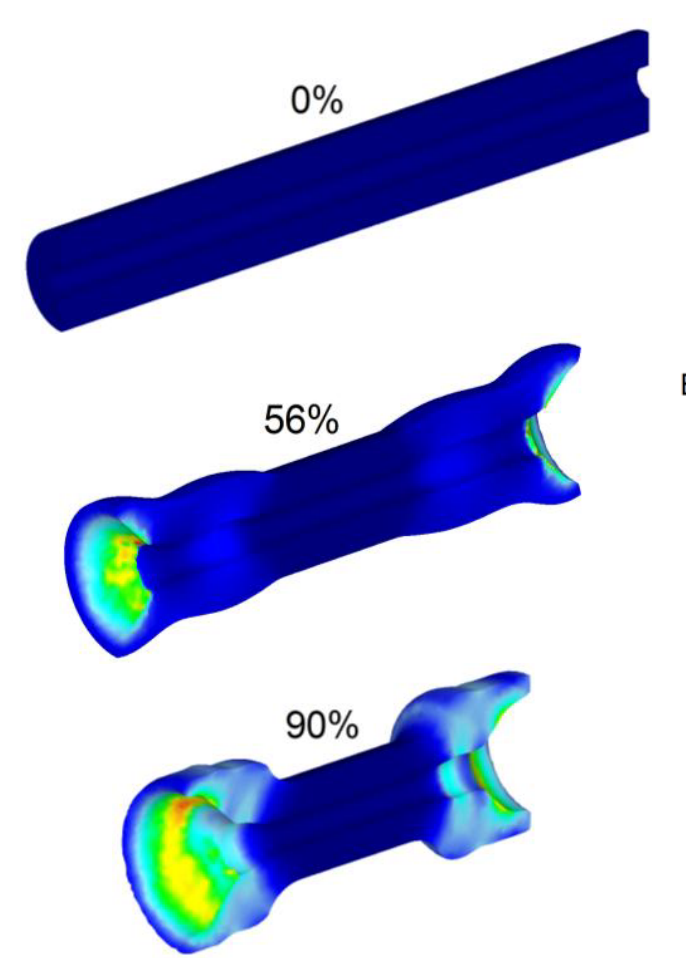

Effective strain

4.0

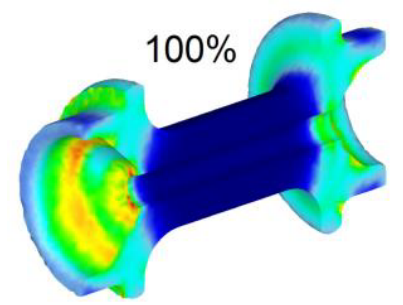

Figure 14. Successive stages of a correctly-run forging process based on Variant II.

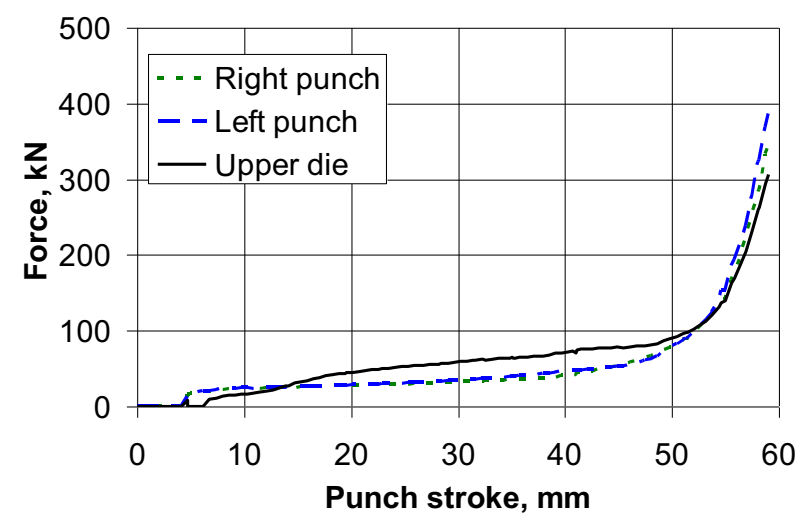

Figure 15. Distribution of forming forces in the process for a bicycle wheel hub according to Variant II - theoretical results.

Fig. 15 illustrates the distribution of forces exerted by individual tools. Their distribution is similar to the one obtained for Variant I: at the beginning of the process, the forces exerted by the side punches increase at a slow rate; at the final stage of the process, when the flanges are being formed, the forces, however, significantly increase their values to $386 \mathrm{kN}$ and $347 \mathrm{kN}$, respectively. The value of the radial force is similar to the values of the forces exerted by the side punches. This is a significant difference compared to the value of the radial force in 
Variant I, in which this force value is almost two times higher than the values of the forces of the side punches. This difference results from establishing a different material forming pattern. In Variant I, the end bosses and flanges are formed in the impression of the clamping dies. In Variant II, the bosses are formed in the impressions made in the side punches, while the flanges are formed by open die forging, which has a significant effect on decreasing values of the radial force.

\section{Comparative analysis of the forging processes}

Based on the theoretical and experimental results, the analyzed forging methods could be compared with respect to material and energy consumption, as well as process safety given the potential occurrence of cracks. Table 1 lists the material balance for individual forging processes. The following are given: billet mass $M_{w}$, forging mass $M_{f}$, flash losses $L_{f}$, machining losses $L_{m}$, and overall material losses $L_{w}$.

The comparison demonstrates that the lowest material losses occur in Variant II of the forging process in a TSFP. A slightly higher material consumption can be observed in Variant I of the TSFP-based forging process. Nonetheless, the most material-consuming process is hammer forging, in which the overall material losses are over four times higher than the losses generated in the forging processes in a TSFP. In addition, the hammer forged forging requires the application of timeconsuming machining to obtain the finished product, which results from substantial technological allowances (no cavities or axial hole).

Table 2 provides information on energy consumption in individual forging processes. As can be seen from the table, hammer forging is the most energy-consuming process, as the amount of energy consumed in this process is over five times higher than in the TSFP-based forging processes. The energy balance does not take into account the operation of billet heating; it should however be emphasized that the billet for hammer forging is heated longer due to a greater diameter. In addition, in the hammer forging process the billet is heated twice, whereas in both variants of the TSFP-based forging process the billet is subjected to heating only once.

Table 1. Comparison of material consumption in the analyzed forging processes

\begin{tabular}{|c|c|c|c|c|c|}
\hline $\begin{array}{c}\text { Forging } \\
\text { method }\end{array}$ & $\begin{array}{c}\boldsymbol{M}_{\boldsymbol{w}} \\
{[\mathbf{k g}]}\end{array}$ & $\begin{array}{c}\boldsymbol{M}_{\boldsymbol{f}} \\
{[\mathbf{k g}]}\end{array}$ & $\begin{array}{c}\boldsymbol{L}_{\boldsymbol{f}} \\
{[\mathbf{k g}]}\end{array}$ & $\begin{array}{c}\boldsymbol{L}_{\boldsymbol{m}} \\
{[\mathbf{k g}]}\end{array}$ & $\begin{array}{c}\boldsymbol{L}_{\boldsymbol{w}} \\
{[\mathbf{k g}]}\end{array}$ \\
\hline Hammer forging & 0,494 & 0,291 & 0,203 & 0,109 & 0,400 \\
\hline $\begin{array}{c}\text { TSFP- } \\
\text { Variant I }\end{array}$ & 0,189 & 0,189 & 0 & 0,095 & 0,095 \\
\hline $\begin{array}{c}\text { TSFP- } \\
\text { Variant II }\end{array}$ & 0,184 & 0,184 & 0 & 0,090 & 0,090 \\
\hline$M_{p}$ - final part mas; $M_{p}=0,094 \mathrm{~kg}$ \\
\hline
\end{tabular}

Table 2. Energy consumption in forging processes

\begin{tabular}{|c|c|c|c|}
\hline $\begin{array}{c}\text { Forging } \\
\text { method }\end{array}$ & $\begin{array}{c}\text { Hammer } \\
\text { forging }\end{array}$ & $\begin{array}{c}\text { TSFP - } \\
\text { Variant I }\end{array}$ & $\begin{array}{c}\text { TSFP - } \\
\text { Variant II }\end{array}$ \\
\hline Energy $[\boldsymbol{k J}]$ & 33,61 & 6,32 & 6,25 \\
\hline
\end{tabular}

The results of the numerical simulations also allowed the analysis of material susceptibility to cracking. To do so, the Cockcroft-Latham (C-L) fracture criterion described by Cockroft and Latham [14] was employed. Implemented in appropriate software, modified model of this criterion was used, according to which the danger of cracking is the larger, the bigger constant $C$ is, described by the equation [15]:

$$
C=\int_{0}^{\varepsilon} \frac{\sigma_{1}}{\sigma_{i}} d \varepsilon
$$

where:

$$
\begin{aligned}
& \sigma_{1}-\text { the largest main stress, } \\
& \sigma_{\mathrm{i}}-\text { equivalent stress, } \\
& \varepsilon-\text { strain, } \\
& C-\text { integral value. }
\end{aligned}
$$

a)

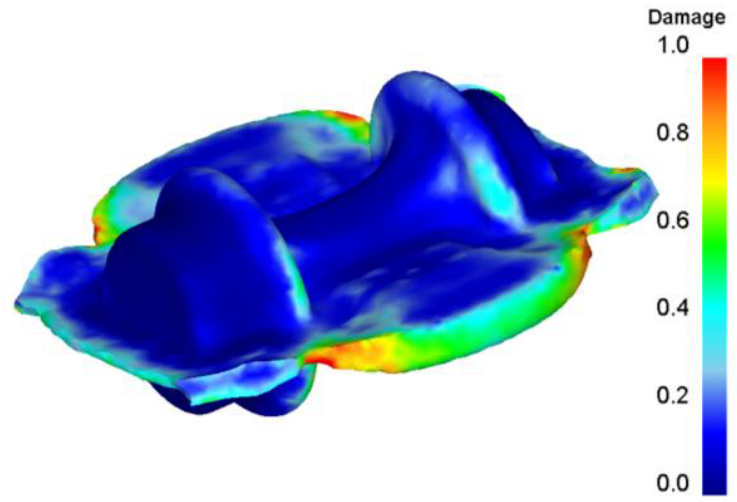

b)

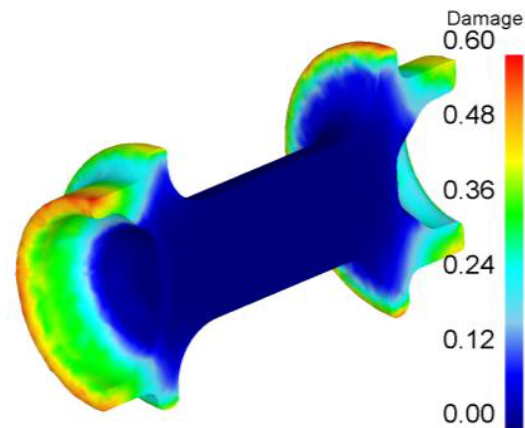

c)

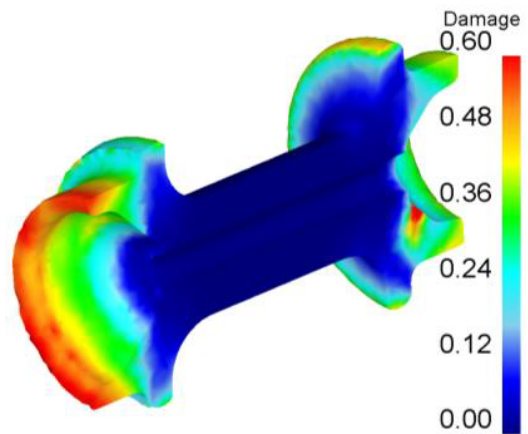

Figure 16. Distribution of the Cockcroft-Latham criterion in the final stage of forging: a) hammer forging, b) TSFP-based forging according to Variant I (cross section), c) TSFP-based forging according to Variant II (cross section).

Fig. 16 shows the distribution of the C-L criterion for each of the analyzed processes. As can be observed, the highest values of this criterion can be found in the region of flash in the hammer forging process. This region will 
be the first to crack. It should however be emphasized that flash is removed, so the occurrence of cracks does not disqualify the product. What is more, industrial practice proves that cracks do not occur in flash. Therefore, it can be claimed that the boundary value of the integral representing the criterion at which cracking occurs is higher for the analyzed aluminum alloy than for the flash; the maximum value of the $\mathrm{C}$ - $\mathrm{L}$ criterion for the flash is over $1.0\left(C_{\text {limit }}>1.0\right)$. Hence, it can be concluded that cracking will not occur in Variants I and II of the TSFP-based forging process, either, because the maximum values of the $\mathrm{C}$ - $\mathrm{L}$ criterion in these processes are lower than in hammer forging and they do not exceed the value of 0.7 .

\section{Conclusions}

The theoretical and experimental investigations have demonstrated that the two developed variants of the forging process for producing a bicycle wheel hub in a three-slide press ensure the production of a part with correct shape and dimensions. Also, the product obtained is free from surface defects such as overlap or cracks. The proposed technologies offer a number of benefits compared to the popular die hammer forging process.

First of all, the motion of the three working tools in a TSFP makes it possible to produce both a bicycle wheel hub forging with axial cavities (Variant I) and a forging additionally equipped with an axial hole (Variant II). As a result, the forging weight is significantly reduced, and machining can be applied to a lesser degree. In addition, material consumption can be reduced if flashless forging is applied. In the two new TSFP-based forging technologies, material losses are over four times lower compared to the hammer forging process.

Secondly, both variants of the TSFP-based forging process are run in one cycle of tool motion. As a result, the processes exhibit low energy consumption. The theoretical calculations have demonstrated that the energy consumption in the processes is over five times lower compared to that in hammer forging.

Furthermore, the short time of forming a bicycle wheel hub forging is a significant advantage in processes for forming aluminum alloys due to a low range of forging temperatures and rapid cooling of these alloys.

One more benefit of the TSFP-based forging processes is related to lower costs of producing tools, which results from the application of dies with small dimensions and from lack of necessity of using tools for flash trimming.

Nonetheless, it should be mentioned that TSFP-based forging processes have certain limitations. First, three- slide forging presses are not produced in series, which means that if a given plant wants to have such machine, it will have to make one on its own. What is more, the tool set used for forging a bicycle wheel hub from a tube billet includes a relatively long mandrel; owing to its slenderness, the mandrel can often get damaged. Finally, from an economic perspective, it should also be noted that a unit price of a tube is higher than the price of a bar with the same outside diameter. This means that producing hollow parts by the method based on Variant 2 is less effective.

Despite the limitations, the presented forging methods have a good potential to forming hollow products. Therefore, further research will be carried out, the aim of which will be to develop a method of forming thin-walled products with thicknesses of relatively large volumes.

\section{References}

1. A. Gontarz, J. Mater. Process. Tech., 177, 228-232 (2006)

2. A. Gontarz, Z. Pater, G. Samołyk, A. Tofil, Steel Res. Int., 81, 358-361 (2010)

3. W. Weroński, A. Gontarz, Z. Pater, J. Mater. Process. Tech., 177, 214-217 (2006)

4. C. Yang, J. Ma, Z. Hu, J. Mater. Process. Tech., 239, 346-358 (2017)

5. P. Wenfei, Z. Shuhua, C. Yijui, S. Xuedao, Z. Lihua, Rare Metal Mat. Eng., 45, 836-842 (2016)

6. J. Bartnicki, Z. Pater, J. Mater. Process. Tech., 155156, 1867-1873 (2004)

7. D. Landgrebe, J. Steger, U. Böhmichen, M. Bergmann, Procedia Manufacturing, 21, 53-59 (2018)

8. X. Huang, B. Wang, J. Lin, C. Zhu, Procedia Engineering, 207, 2376-2381 (2017)

9. Z. Pater, A. Gontarz, J. Tomczak, T. Bulzak, Arch. Civ. Mech. Eng., 15, 917-924 (2015)

10. R. Neugebauer, R. Glass, M. Hoffmann, CIRP Ann.Manuf. Techn., 54, 241-244 (2005)

11. A. Gontarz, Z. Pater, Engineering Transactions, 47, 339-343 (1999)

12. A. Gontarz, A. Dziubińska, Ł. Okoń, Arch. Metall. Mater., 56, 379-384 (2011)

13. Y.H. Kim, T.K. Ryou, H.J. Choi, B.B. Hwang, J. Mater. Process. Tech., 123, 270-276 (2002)

14. M.G. Cockcroft, D.J. Latham, J. I. Met., 96, 33-39 (1968)

15. K.H. Shim, S.K. Lee, B.S. Kang, S.M. Hwang, J. Mater. Process. Tech., 155-156, 1935-1942 (2004) 